\title{
Esophageal cancer with right vertebral artery variation observed during thoracoscopic esophagectomy: a case report
}

\author{
Yuta Sato, Yoshihiro Tanaka* @i], Takeharu Imai, Yuji Hatanaka, Naoki Okumura, Nobuhisa Matsuhashi, \\ Takao Takahashi and Kazuhiro Yoshida
}

\begin{abstract}
Background: Variation of the vertebral artery bifurcation is rare. This branching abnormality can cause unexpected vertebral artery damage and bleeding during thoracoscopic esophagectomy. There are few reports of abnormal branching of the vertebral artery associated with neurosurgery but none related to esophagectomy. We report the case together with the results of the evaluation of vertebral artery bifurcation and length in 50 patients with esophageal cancer in our hospital.
\end{abstract}

Case presentation: Thoracoscopic esophagectomy was performed on a 70-year-old patient with esophageal cancer. During lymph node dissection around the right reccurent laryngeal nerve, an unusual blood vessel was found running along the right subclavian artery. We determined this blood vessel to be the right vertebral artery branching far more centrally than usual. Because this anatomical abnormality was clarified, we could then recognize that the right reccurent laryngeal nerve coursed around the right vertebral artery and the right subclavian artery and thus was running in a larger arch than usual.

Conclusion: Long right vertebral artery may appear in the surgical field of the thoracoscopic esophagectomy. Knowledge of such anatomical variation is important to prevent iatrogenic injury of the right vertebral artery and the right reccurent laryngeal nerve.

Keywords: Vertebral artery, Recurrent laryngeal nerve, Thoracoscopic esophagectomy

\section{Background}

The vertebral artery usually takes its origin from the subclavian artery and ascends to enter the transverse foramen of the sixth cervical vertebra [1]. There are some reports on variations of vertebral artery bifurcation [2-6], but none as they relate to esophagectomy. Knowledge of such anatomical variation is important in thoracoscopic esophagectomy to prevent iatrogenic injury of

*Correspondence: yoshihirotana11@hotmail.com

Department of Surgical Oncology, Gifu Graduate School of Medicine, 1-1 Yanagido, Gifu City 501-1194, Japan the right vertebral artery (RVA) and the right reccurent laryngeal nerve (RLN).

\section{Case presentation}

A 70-year-old man with a height of $161.0 \mathrm{~cm}$, weight of $54.6 \mathrm{~kg}$, and body mass index of $21.0 \mathrm{~kg} / \mathrm{m}^{2}$ complained of difficulty in swallowing a meal and was referred from another hospital. He was diagnosed as having thoracic esophageal cancer (T3N1M0, Stage IIIA). We performed thoracoscopic esophagectomy in the prone position, two-fields lymphnode dissection, subtotal gastric tube reconstruction via the posterior mediastinal route, and jejunostomy after 2 courses of chemotherapy (bi-weekly 
DCF: docetaxel $35 \mathrm{mg} / \mathrm{m}^{2}$, cisplatin $40 \mathrm{mg} / \mathrm{m}^{2}$, fluorouracil $400 \mathrm{mg} / \mathrm{m}^{2}$ ) [7]. The thoracoscopic operation time was $299 \mathrm{~min}$, and blood loss was $20 \mathrm{ml}$. During lymph node dissection around the right RLN, an unusual blood vessel was found running along the right subclavian artery (RSA). We assumed that the blood vessel was the RVA, which was very long at $7.02 \mathrm{~cm}$ (Fig. 1). Because this anatomical abnormality was clarified, we could recognize that the right RLN coursed around the RVA and the RSA and thus was running in a larger arch than usual. As a result, lymph node dissection could be performed safely without damaging the RVA and the right RLN, and no metastasis was found in the excised station number of 106recR.

\section{Discussion and conclusions}

The RSA branches from the brachiocephalic artery, runs laterally across the anterior and middle oblique muscles, and bifurcates into the RVA as its first branch. The RVA often enters the transverse process of the sixth cervical vertebra after bifurcation. In the presented case, the RVA branched from the RSA at a very central location, so it appeared in the surgical field during lymph node dissection around the right RLN as an unusual blood vessel running along the RSA.

In the vertebral artery, the segment from the bifurcation of the RSA to the transverse process of the vertebral body is called the V1 segment [8]. In a study of 266 cases, Woraputtaporn et al. reported that the average length of the RVA and left vertebral artery (LVA) V1 segments was $3.88 \pm 1.14 \mathrm{~cm}$ [9]. The average length of the RVA was $3.69 \mathrm{~cm}$ and that of the LVA was $4.14 \mathrm{~cm}$ for 50 esophageal cancer patients operated on at our hospital. This is almost the same as those reported by Woraputtaporn et al. but V1 of the RVA of our presented case was $7.02 \mathrm{~cm}$ (Fig. 2), which was very long.

Several variations have been reported at the origin of the RVA, and Newton and Potts classified them [10]. Type A, which branches within $2 \mathrm{~cm}$ from the thyrocervical trunk, is reported to be the most common at $83.12 \%$, and Type B, which branches more than $2 \mathrm{~cm}$ away from the thyrocervical trunk, is much less common at $8.27 \%$ (Fig. 3). In the 50 patients with esophageal cancer in our hospital, Type A was seen in 45 patients (90\%) and Type $\mathrm{B}$, including that in the presented case, was seen in 5 patients (10\%). The length of the V1 segment was compared between Type A and B. The median RVA

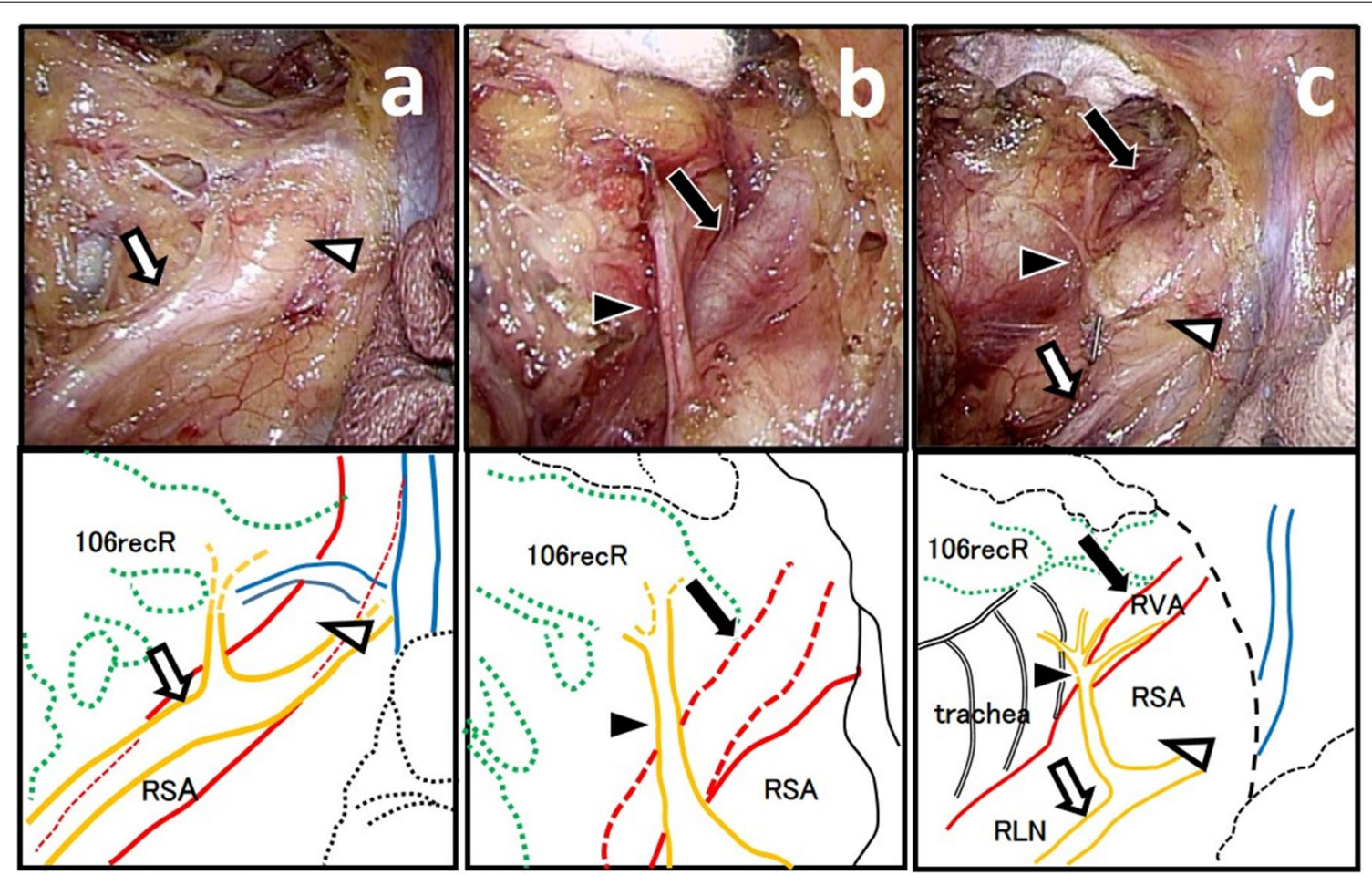

Fig. 1 An unusual blood vessel running along the right subclavian artery was found during a thoracoscopic esophagectomy. a As with normal anatomy, the right vagus nerve (white arrow) running on the dorsal side of the right subclavian artery (white arrowhead). b An unusual blood vessel (black arrow) was found on the ventral side of the right recurrent laryngeal nerve (black arrowhead). c We determined this unusual blood vessel (black arrow) to be the right vertebral artery. Show the surgical field after dissection was completed 


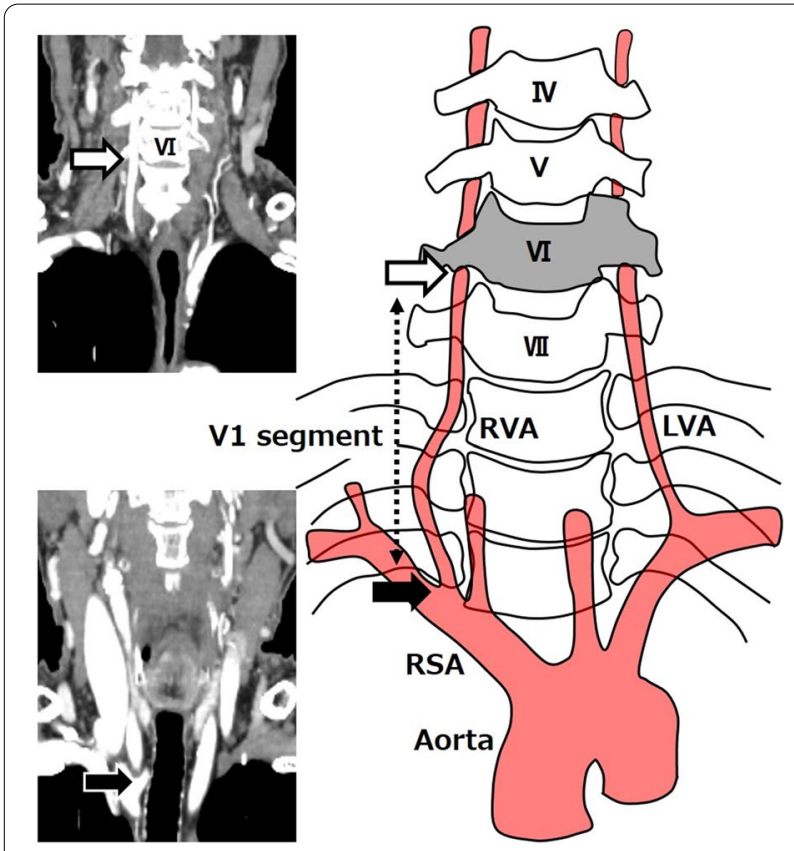

Fig. 2 Preoperative CT image of the patient presented in our case. The RVA from the bifurcation of the SRA (black arrow) to the transverse process of the sixth vertebral body (white arrow) is called segment $\mathrm{V} 1$. In the presented case, $\mathrm{V} 1$ oh the RVA was $7.02 \mathrm{~cm}$
Table 1 Median length of vertebral artery, height and weight of 50 patients in our hospital

\begin{tabular}{llll}
\hline & Type A & Type B & P Value \\
\hline Number of cases & $\mathrm{n}=45$ & $\mathrm{n}=5$ & \\
Length of RVA $(\mathrm{cm})$ & $3.56[1.87-5.24]$ & $5.05[4.12-7.02]$ & 0.0020 \\
Length of LVA $(\mathrm{cm})$ & $3.96[2.05-8.89]$ & $4.47[3.78-5.08]$ & 0.1501 \\
Height $(\mathrm{cm})$ & $163.0[147.1-178]$ & $168.3[161.4-170.1]$ & 0.2014 \\
Weight $(\mathrm{kg})$ & $51.8[36.7-89.1]$ & $57.0[40.1-65.9]$ & 0.3483 \\
\hline
\end{tabular}

The Mann-Whitney test was used for continuous variables. A $p$ value of less than 0.05 was considered to be statistically significant

RVA right vertebral artery, LVA left vertebral artery

length of Type B was $5.05 \mathrm{~cm}$, which was significantly longer than $3.56 \mathrm{~cm}$ measured in the RVA length of Type A $(p=0.0020)$, although there were no significant differences in patients' height between Type A and Type B (Table 1).

We considered that the RVA length of Type B might be longer than Type A because the RVA branched from the central side of the RSA in Type B. So, the RVA of Type B may be visible like our case in the surgical field, we will see the right RLN as if which was ascending across the two subclavian arteries, during lymph node dissection

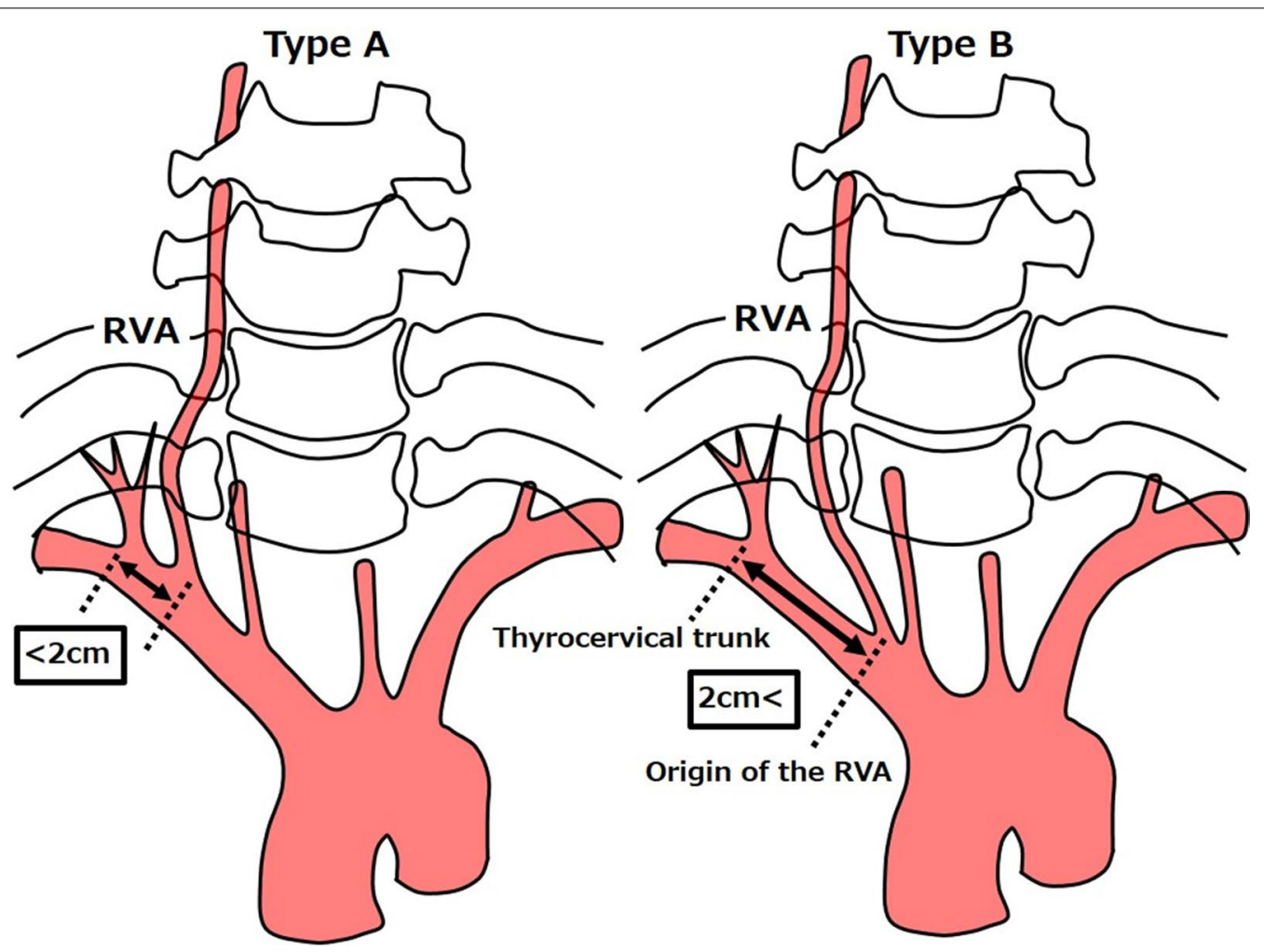

Fig. 3 In Type A, the RVA branches within $2 \mathrm{~cm}$ from the thyrocervical trunk, whereas in Type B, the RVA branches more than $2 \mathrm{~cm}$ away from the thyrocervical trunk 
around the right RLN in thoracoscopic esophagectomy. In this type, the right RLN coursed around the RVA and the RSA and thus was running in a larger arch than usual. Therefore, preoperative understanding of RVA variation can prevent unexpected injury of the RVA and the right RLN and provide safe lymph node dissection around the right RLN in thoracoscopic esophagectomy.

\section{Abbreviations}

RVA: Right vertebral artery; RLN: Recurrent laryngeal nerve; RSA: Right subclavian artery; LVA: Left vertebral artery; CT: Computed tomography.

\section{Acknowledgements}

We thank rise japan LLC for English language editing.

\section{Authors' contributions}

YS drafted the manuscript. KY and YT performed the operation. TI and YH participated in the operation. NO, NM and TT provided academic advice. All authors read and approved the final manuscript.

\section{Funding}

Funding information is not applicable.

\section{Availability of data and materials}

Not applicable.

\section{Declarations}

\section{Ethics approval and consent to participate}

This case report was approved by the ethics committee of Gifu University School of Medicine (approved ID: 2020-172).

\section{Consent for publication}

Written informed consent was obtained from the patient for publication of this case report and accompanying images. A copy of the patient's written consent is available for review by the Editor-in-Chief of this journal.

\section{Competing interests}

Kazuhiro Yoshida has received research funding from Asahi KASEI Co., Ltd., CHUGAI PHARMACEUTICAL CO., LTD., Covidien Japan, DAIICHI SANKYO COMPANY, LIMITED, Eisai Co., Ltd., Eli Lilly Japan K.K., Johnson \& Johnson K.K., Merck Serono Co., Ltd., MSD K.K., Nippon Kayaku Co., Ltd., Novartis Pharma K.K., ONO PHARMACEUTICAL CO., LTD., Otsuka Pharmaceutical Co., Ltd., Sanofi K.K., TAIHO PHARMACEUTICAL CO., LTD., Takeda Pharmaceutical Co., Ltd., TSUMURA \& CO., Yakult Honsha Co. Ltd., ABBOTT JAPAN CO., LTD., AbbVie GK, Astellas Pharma Inc., Biogen Japan Ltd., CELGENE CORPORATION, GlaxoSmithKline K.K., KCl, Koninklijke Philips N.V., Kyouwa Hakkou Kirin Co., Ltd., Meiji Seika Pharma Co., Ltd., Toray Medical Co., Ltd., KAKEN PHARMACEUTICAL CO., LTD.; honoraria from Asahi KASEI Co., Ltd., CHUGAI PHARMACEUTICAL CO., LTD., Covidien Japan, DAIICHI SANKYO COMPANY, LIMITED, Eisai Co., Ltd., Eli Lilly Japan K.K., Johnson \& Johnson K.K., Merck Serono Co., Ltd., MSD K.K., Nippon Kayaku Co., Ltd., Novartis Pharma K.K., ONO PHARMACEUTICAL CO., LTD., Otsuka Pharmaceutical Co., Ltd., Sanofi K.K., TAIHO PHARMACEUTICAL CO., LTD., Takeda Pharmaceutical Co., Ltd., TSUMURA \& CO., Yakult Honsha Co., Ltd., AstraZeneca K.K., Bristol-Myers Squibb., Denka Company Limited, EA Pharma Co., Ltd., Olympus Corporation., Pfizer Japan Inc., SANWA KAGAKU KENKYUSHO CO., LTD., SBI Pharmaceuticals Co., Ltd., TEIJIN PHARMA LIMITED., Terumo Corporation; and others from Yakult Honsha Co., Ltd. (no involvement in intellectual property) outside the submitted work. Yoshihiro Tanaka and other co-authors declare that they have no conflicts of interest.

Received: 14 January 2021 Accepted: 20 April 2021

Published online: 27 April 2021

\section{References}

1. Maiti TK, Konar SK, Bir S, Nanda A, Cuellar H. Anomalous origin of the right vertebral artery: incidence and significance. World Neurosurg. 2016;89:601-10.

2. Akdeniz B, Yilmaz E, Pekel N, Ergul BU. Anomalous origin of the right vertebral artery from the ascending aorta in the presence of an aberrant right subclavian artery. Int J Cardiovasc Imaging. 2007;23:39-42.

3. Poynter C. Arterial anomalies pertaining to the aortic arches and the branches arising from them. Nebr Univ Stud. 1916;16:229-345.

4. Wasserman BA, Mikulis DJ, Manzione JV. Origin of the right vertebral artery from the left side of the aortic arch proximal to the origin of the left subclavian artery. AJNR Am J Neuroradiol. 1992;13:355-8.

5. Albayram S, Gailloud P, Wasserman BA. Bilateral arch origin of the vertebral arteries. AJNR Am J Neuroradiol. 2002;23:455-8.

6. Argenson C, Francke J, Sylla S, Dintimille H, Papasian S, diMarino V. The vertebral arteries (segments V1 and V2). Anat Clin. 1980;2:29-32.

7. Tanaka Y, Yoshida K, Yamada A, Tanahashi T, Okumura N, Matsuhashi N, et al. Phase II trial of biweekly docetaxel, cisplatin, and 5-fluorouracil chemotherapy for advanced esophageal squamous cell carcinoma. Cancer Chemother Pharmacol. 2016;77:1143-52.

8. Bruneau M, Cornelius JF, Marneffe V, Triffaux M, George B. Anatomical variation of the V2 segment of the vertebral artery. Oper Neurosurg. 2006;59(Suppl 1):20-4.

9. Woraputtaporn W, Ananteerakul T, lamsaard S, Namking M. Incidence of vertebral artery of aortic arch origin, its level of entry into transverse foramen, length, diameter and clinical significance. Ant Sci Int. 2019;94:275-9.

10. Newton TH, Potts DG. Radiology of the skull and brain ANGIOGRAPHY vol2 arteries. Saint Louis: C.V. Mosby Company; 1974. p. 1659-795.

\section{Publisher's Note}

Springer Nature remains neutral with regard to jurisdictional claims in published maps and institutional affiliations.

Ready to submit your research? Choose BMC and benefit from:

- fast, convenient online submission

- thorough peer review by experienced researchers in your field

- rapid publication on acceptance

- support for research data, including large and complex data types

- gold Open Access which fosters wider collaboration and increased citations

- maximum visibility for your research: over $100 \mathrm{M}$ website views per year

At BMC, research is always in progress.

Learn more biomedcentral.com/submissions 